\title{
An automated flow system incorporating in-line acid dissolution of bismuth metal from a cyclotron irradiated target assembly for use in the isolation of astatine-211
}

Matthew J. O’Hara' ${ }^{1 *}$, Anthony J. Krzysko ${ }^{1}$, Cynthia M. Niver ${ }^{1}$, Samuel S. Morrison ${ }^{1}$, Stanley L. Owsley, Jr. ${ }^{1}$, Donald K. Hamlin², Eric F. Dorman², D. Scott Wilbur ${ }^{2}$

\begin{abstract}
Astatine-211 $\left({ }^{211} \mathrm{At}\right)$ is a promising cyclotron-produced radionuclide being investigated for use in targeted alpha therapy. The wet chemical isolation of trace quantities of ${ }^{211} \mathrm{At}$, produced within several grams of Bi metal deposited onto an aluminum cyclotron target assembly, involves a multi-step procedure. Because the ${ }^{211}$ At isolation method is labor-intensive and complex, automation of the method is being developed to facilitate routine processing at the University of Washington and to make it easier to transfer the process to other institutions. As part of that automation effort, a module useful in the initial step of the isolation procedure, dissolution of the Bi target, was designed and tested. The computer-controlled module performs in-line dissolution of Bi metal from the target assembly using an enclosed target dissolution
\end{abstract}


block, routing the resulting solubilized ${ }^{211} \mathrm{At} / \mathrm{Bi}$ mixture to the subsequent process step. The primary parameters involved in Bi metal solubilization (influent $\mathrm{HNO}_{3}$ concentration and flow rate) were optimized prior to evaluation of the system using replicate ${ }^{211}$ At-bearing cyclotron irradiated targets. The results indicate that the system performs in a predictable and reproducible manner, with cumulative $\mathrm{Bi}$ and ${ }^{211} \mathrm{At}$ recoveries following a sigmoidal function.

\section{KEYWORDS}

Astatine-211, ${ }^{211} \mathrm{At}$; cyclotron target; radioimmunotherapy; targeted alpha therapy; laboratory automation; bismuth metal dissolution

\section{Introduction}

Radioimmunotherapy agents containing alpha particle-emitting radionuclides ( $\alpha$-RIT) are being investigated for treatment of many cancer types (Allen et al., 2004; Couturier et al., 2005; Hassfjell and Brechbiel, 2001; McDevitt et al., 1998; Mulford et al., 2005; Zalutsky and Pozzi, 2004). Alpha radiation is highly cytotoxic over a short range, as it has very high linear energy transfer (LET, typically $60-230 \mathrm{keV} \cdot \mu \mathrm{m}^{-1}$ ) with particle path lengths that transect only a few cells (Hassfjell and Brechbiel, 2001). Cellular damage in surrounding healthy cells is therefore minimized (Mulford et al., 2005). Hence, $\alpha$-RIT has promise for high specificity and efficacy. The short path length of the alpha particle makes ${ }^{211}$ At-labeled radiopharmaceutical use questionable for treatment of solid tumors, but a recent publication has demonstrated that fractionated $\alpha$-RIT can be effective in treating solid tumor xenografts in a murine model (Bäck et al., 2016). While the use of alpha radiation in treating solid tumors has been questioned and needs to be further evaluated (Barbet and Chatal, 2011; Behr et al., 1999), there is general agreement that $\alpha$-RIT holds great promise for treatment of (micro)metastatic and disseminated 
cancers (Dahle et al., 2011; Green et al., 2015; Jurcic et al., 2002; Orozco et al., 2013; Rosenblat et al., 2010), in addition to treatment of minimal residual disease after surgery and/or use of other treatment modalities (Zalutsky et al., 2008).

There are ten alpha-emitting radionuclides that have been identified as having appropriate properties for human use (Wilbur, 2011). Of those radionuclides, astatine-211 $\left({ }^{211} \mathrm{At}\right)$ is of high interest (Guerard et al., 2013; Wilbur, 2008; Zalutsky et al., 2007), as its branched alpha decay between ${ }^{211}$ At and ${ }^{211}$ Po does not generate subsequent alpha-emitting daughters that could localize in normal tissues and cause unwanted toxicity. The short half-life $(7.21 \mathrm{~h})$ is also attractive for clinical use, as it may minimize hospitalization time. To date, two studies with ${ }^{211}$ At-labeled monoclonal antibodies have progressed to clinical trials. In one clinical trial, chimeric antitenascin monoclonal antibody $81 \mathrm{C} 6$ treatment was administered within surgical resection cavities of malignant brain tumor patients (Zalutsky et al., 2008). In another trial, MX35 F(ab’) 2 was administered into the peritoneal cavity for treatment of ovarian cancer (Andersson et al., 2009). Future clinical trials are planned at the Fred Hutchinson Cancer Research Center and the University of Washington using $\alpha$-RIT with ${ }^{211}$ At for treatment of blood-borne cancers (lymphoma, leukemia, multiple myeloma, etc.).

Astatine-211 is produced using alpha beam irradiation of naturally monoisotopic $\mathrm{Bi}\left({ }^{209} \mathrm{Bi}\right)$ via the $(\alpha, 2$ n) reaction (Johnson et al., 1949; Zalutsky and Pruszynski, 2011). Because only a few locations in the U.S. possess cyclotrons capable of producing alpha beams with sufficient energy (i.e., 28-29 MeV) for production of ${ }^{211} \mathrm{At}$, development of targeted alpha therapy agents with this radionuclide has been slow (Zalutsky and Pruszynski, 2011). The fact that the University of Washington Medical Cyclotron Facility has a Scanditronix MC-50 cyclotron with 
the capability to produce ${ }^{211}$ At has allowed investigations into the development of new cancer therapy agents there and at the Fred Hutchinson Cancer Research Center (Seattle, WA). Encouraging results from those studies prompted an upgrade of a cyclotron target station to produce large enough ${ }^{211}$ At quantities (e.g., $>4 \mathrm{GBq}$ ) for the clinical trials to be conducted.

After target irradiation, the ${ }^{211}$ At must be isolated from the Bi target expeditiously and with high recovery. That isolation process involves separation of trace quantities of ${ }^{211} \mathrm{At}$ from cyclotron targets containing as much as $5 \mathrm{~g} \mathrm{Bi}$ metal. With a specific activity of $76 \mathrm{GBq} \cdot \mu \mathrm{g}^{-1}$, a typical ${ }^{211}$ At production run of $\sim 1.1 \mathrm{GBq}(\sim 29 \mathrm{mCi})$ represents only $\sim 14 \mathrm{ng}$ of ${ }^{211} \mathrm{At}$. Astatine-211 is obtained with high radionuclidic purity when the cyclotron beam is maintained at $\leq 29 \mathrm{MeV}$ (Gagnon et al., 2012; Groppi et al., 2005; IAEA, 2009); there are no stable nuclides of this element.

Two methods for the isolation of ${ }^{211} \mathrm{At}$ from Bi metal are predominantly in use. One method is dry distillation from molten Bi metal targets (Aneheim et al., 2015a; Johnson et al., 1949; Lambrecht and Mirzadeh, 1985; Lindegren et al., 2001; Wilbur et al., 1991). The second method is chemical purification using wet chemistry, which involves dissolution of the Bi metal target followed by solvent extraction (Alliot et al., 2009; Balkin et al., 2013; Groppi et al., 2005; Neirinckx and Smit, 1973; Neumann, 1957; Sultana et al., 2000; Yordanov et al., 2004; Zona et al., 2008). Both methods of ${ }^{211}$ At isolation from irradiated targets are technically difficult to conduct.

Although dry distillation is at present the most widely used isolation method, an increase in the Bi target size for clinical level production of ${ }^{211} \mathrm{At}$ made that route less attractive for our studies. Therefore, the wet chemistry isolation approach was optimized for studies at the 
University of Washington (Balkin et al., 2013). Briefly, the isolation of trace quantities of ${ }^{211} \mathrm{At}$, produced within several grams of a Bi metal target, involves a complex, multi-step procedure:

(1) Bi metal dissolution in high concentration $\mathrm{HNO}_{3}$, (2) distillation of the $\mathrm{HNO}_{3}$ to yield Bi salts containing ${ }^{211} \mathrm{At}$, (3) dissolution of the salts in $8 \mathrm{M} \mathrm{HCl}$, (4) solvent extraction of ${ }^{211} \mathrm{At}$ from dissolved Bi salts with diisopropyl ether (DIPE), (5) repetitive washing of the DIPE with clean acid, and (6) back-extraction of ${ }^{211} \mathrm{At}$ from DIPE into $4 \mathrm{M} \mathrm{NaOH}$, leading to a purified ${ }^{211} \mathrm{At}$ product.

With the desire to be able to expand clinical studies to other institutions (in Phase II/III clinical trials), the efficiency and reproducibility of the currently manual ${ }^{211} \mathrm{At}$ isolation process must be improved. Therefore, we believe it is imperative that the isolation process be automated, such that it can be conducted in the same manner at several institutions. A research team has developed a method for automated production of astatinated antibodies based on the dry distillation approach (Aneheim et al., 2015a; Aneheim et al., 2015b). In contrast to those studies, this team is exploring new approaches to isolate ${ }^{211} \mathrm{At}$ using wet chemistry methods that are conducive to automation by computer-controlled fluidics (Wooten et al., 2016).

As a part of our effort to automate the ${ }^{211}$ At isolation process, we herein report the design and testing of a simple and effective device for the in-line dissolution of irradiated Bi metal targets using a remotely controlled fluid delivery system. This research effort is an important first step in the automation of the manual ${ }^{211}$ At isolation method described by Balkin et al., wherein irradiated Bi metal, deposited on an Al target backing, is initially dissolved in an open bath of concentrated nitric acid (Balkin et al., 2013). The updated process reported here employs a computer controlled fluid delivery pump coupled to a target dissolution block (TDB) to pass a 
thin film of a dissolution reagent (nitric acid) across the Bi metal surface within an enclosed assembly. The TDB is a simple 2-piece clamp-together apparatus that seals the Bi target assembly within. Influent and effluent ports allow the dissolving solution to be passed from a digital syringe pump, through the TDB, and out to a collection vessel. The dissolved target solution is then used in the subsequent steps in the ${ }^{211}$ At isolation process (steps (2) through (6) described above).

Experimental work was performed in three general steps, and will be presented accordingly: First, an assessment of the $\mathrm{Bi} / \mathrm{HNO}_{3}$ reaction and reaction by-products was made, and the rate of dissolution of $\mathrm{Bi}$ metal across a range $\mathrm{HNO}_{3}$ solutions was evaluated in open vessels. The resulting data allowed for the modeling of a surface area normalized Bi dissolution rate function. Next, in-line Bi dissolution performance was evaluated using the TDB. The effects of $\mathrm{HNO}_{3}$ concentration and influent flow rate were assessed to identify the optimal process parameters. Additionally, the observed dissolution rates between open-vessel and in-line Bi dissolution were compared. Finally, following optimization of dissolution parameters for the TDB module, the optimized method was performed on several cyclotron irradiated Bi target assemblies. Mapping of the $\mathrm{Bi}$ dissolution and ${ }^{211}$ At release profiles indicated virtually quantitative and reproducible system performance. Furthermore, the cumulative Bi and ${ }^{211}$ At release profiles model as sigmoidal functions. The predictable nature of the ${ }^{211}$ At release profile allows the user to tune the system to meet target processing requirements. 


\section{Experimental}

\subsection{Reagents and materials}

Reagent grade and Optima ${ }^{\mathrm{TM}}$ grade nitric acid (Fisher Scientific, Waltham, MA) was used for Bi target dissolution. All solutions were prepared from deionized water $(18.3 \mathrm{M} \Omega \cdot \mathrm{cm}) \mathrm{using}$ a Barnstead Nanopure Diamond water purification system (Dubuque, IA). Scintillation cocktail was Ultima Gold ${ }^{\mathrm{TM}}$ AB (PerkinElmer, Waltham, MA). Bi pellets of 99.999\% purity, used in the manufacture of Bi target assemblies, were acquired from Alfa Aesar (Ward Hill, MA). Off-line Bi dissolution rate studies used cylindrical Bi pieces of the same purity (Sigma-Aldrich, St.

Louis, MO). ACS reagent grade bismuth nitrate pentahydrate $\left(\mathrm{Bi}\left(\mathrm{NO}_{3}\right)_{3} \cdot 5 \mathrm{H}_{2} \mathrm{O}\right)$ was purchased from Sigma-Aldrich.

\section{$2.2{ }^{211}$ At production}

Astatine-211 is produced via the ${ }^{209} \mathrm{Bi}(\alpha, 2 n)^{211}$ At reaction at the University of Washington Medical Cyclotron Facility (UWMCF) using a Scanditronix MC-50 cyclotron. The cyclotron is capable of producing external alpha beams $\left(\mathrm{He}^{2+}\right)$ in the energy range of $27.0-47.3 \mathrm{MeV}$. For the ${ }^{211}$ At production, a $29.0 \mathrm{MeV}$ alpha beam is utilized; typical electric currents on the target are 30 to $50 \mu \mathrm{A}$. The Bi target is placed in a 10 degree slanted target station on a dedicated isotope production beamline. A beam integrator is used during irradiations to attain a consistent integrated current of either 36 or $38 \mu \mathrm{A} \cdot \mathrm{h}$. The design, preparation, and performance of the $\mathrm{Bi}$ metal cyclotron targets has been described (Gagnon et al., 2012). The deposited Bi metal film is approximately $0.3 \mathrm{~mm}$ thick and has a surface area of $16.8 \mathrm{~cm}^{2}(1.41 \mathrm{~cm} \times 11.92 \mathrm{~cm})$. 


\subsection{Fluidic system configuration}

The simple fluid delivery system that was assembled to evaluate the performance of an inline Bi target dissolution block (TDB) is depicted in Figure 1. The system is comprised of a 48,000 step digital syringe pump (SP) coupled to a 6 position distribution valve (Norgren, Las Vegas, NV). The SP is configured with a $10 \mathrm{~mL}$ displacement syringe (Flex Fluidics, Las Vegas, NV). The pump is assembled into a metal box provided by J-Kem (St. Louis, MO), and is operated by a customized version of Kem-Pump software. The system is plumbed using 0.75 mm ID x 1/16" OD Teflon ${ }^{\circledR}$ fluorinated ethylene propylene (FEP) tubing for reagent transport lines. Lines are connected to the distribution valve and the inlet/outlet ports of the TDB using PEEK $1 / 4-28$ flangeless nuts with Tefzel ${ }^{\circledR}$ (ethylene tetrafluoroethylene (ETFE)) ferrules (Upchurch Scientific, Oak Harbor, WA). Tubing is connected to five of the six SP distribution valve ports to enable filling the syringe with: (1) air, (2) water, or (3) $10 \mathrm{M} \mathrm{HNO}_{3}$, and to deliver fluids to: (4) waste or (5) the TDB. The one remaining port is sealed with a threaded plug.

Images of the disassembled and assembled TDB are shown in Figure 2A and 2B, respectively. The device is machined from amorphous thermoplastic polyetherimide $\left(\mathrm{ULTEM}^{\mathrm{TM}}\right)$ and is comprised of three parts: the rear panel (RP), front panel (FP), and stand (S). To assemble the TDB, the Bi target assembly (T) is dropped into the RP, after which the FP is placed in position over the RP using three Teflon guide rods, and the two pieces are adjoined via clamps. When the RP and FP are assembled, the dimensions are 7.62 (w) $\times 5.08$ (d) $\times 17.78$ (h) $\mathrm{cm}$. A Viton ${ }^{\mathrm{TM}} \mathrm{O}$-ring forms a seal between the $\mathrm{FP}$ and the thin aluminum metal rim that surrounds the embedded and polished Bi metal target. The region inside the O-ring contains a machined flow channel that is $0.305 \mathrm{~mm}(\mathrm{~d}) \times 1.41 \mathrm{~cm}(\mathrm{w}) \times 11.92 \mathrm{~cm}(1)\left(\right.$ volume $\left.=0.513 \mathrm{~cm}^{3}\right)$ 
into which influents can enter from the fluid port at the bottom and exit at the top. A liquid reservoir is machined into the bottom of the stand (S) to catch dissolved Bi metal in the event of a breach in the O-ring seal between the FP and the Bi target assembly.

When the fluidic system delivered $\mathrm{HNO}_{3}$ to the TDB, the effluent fractions containing dissolved Bi salts were collected via the effluent tube using a fraction collector for non-irradiated targets, and manually when dissolving irradiated targets within a radiological glovebox.

The residence time $\left(t_{r}\right)$ of $\mathrm{HNO}_{3}$ flowing through the TDB is dependent on the flow rate of the reagent delivery pump, as given by eq 1 ,

where $V$ is the volume of the TDB flow channel $\left(0.513 \mathrm{~cm}^{3}\right)$, and $R_{f}$ is the flow rate $\left(\mathrm{mL} \cdot \mathrm{s}^{-1}\right)$.

\subsection{Bi target dissolution procedure}

The protocols for dissolving Bi targets are summarized in Table 1: (1) Assemble Bi target into the TDB rear panel, then attach front panel and clamp together, then insert the TDB into the stand. (2) Perform the leak test protocol, and (3) assure that there is a positive O-ring seal between the TDB front panel and the $\mathrm{Al}$ frame of the Bi target assembly. This is accomplished by visually inspecting the bottom of the TDB to assure there was not leakage of water following the leak test. (4) Perform the target dissolution protocol, which delivers a programmed volume of $\mathrm{HNO}_{3}$ from the SP to the TDB influent line at a programmed flow rate. (5) At the conclusion of the target dissolution protocol, the TDB clean-up protocol delivers air to purge the $\mathrm{HNO}_{3}$ from the system, then washes the lines and TDB flow channel with water, and finally purges the rinse 
water with air. (6) The spent Bi target assembly can be removed and the TDB rinsed with water, dried, and stored for reuse.

For purposes of this study, the dissolved Bi effluents were collected into separate fractions so that the $\mathrm{Bi}$ concentration and ${ }^{211}$ At activity concentration could be measured as a function of $\mathrm{HNO}_{3}$ effluent volume. Otherwise, the TDB effluents are intended to be routed to a distillation apparatus so the $\mathrm{HNO}_{3}$ can be distilled to give a $\mathrm{Bi}$ nitrate salt residue prior to the subsequent

${ }^{211}$ At solvent extraction step (see process steps (2) through (6) listed in Introduction).

\section{$2.5^{211}$ At analysis}

The TDB effluent fractions collected from irradiated target processing were immediately analyzed using a Capintec CRC-15R dose calibrator (Ramsey, NJ). However, high concentrations of $\mathrm{Bi}$ in solution attenuates the low energy ${ }^{211} \mathrm{At}$ and progeny $\mathrm{X}$-ray and gamma emissions, resulting in low, inaccurate activity readings (Balkin et al., 2013). Since Bi concentrations in the collected TDB effluents were anticipated to range considerably across the dissolution process, use of the dose calibrator was avoided, except in one case. That case is the measurement of the ${ }^{211} \mathrm{At}$ activity remaining on the Al target backing surface after removal of the Bi. That measurement indicated that less than $1 \%$ of the ${ }^{211}$ At activity remained on the target backing ( $>99 \%{ }^{211}$ At activity was removed in the dissolution process).

Liquid scintillation analysis (LSA) was performed on dilutions of each of the collected target dissolution fractions to obtain the activity of the ${ }^{211} \mathrm{At} /{ }^{211} \mathrm{Po}$ alpha particle emissions rather than using the dose calibrator, which was susceptible to X-ray and gamma energy attenuation. A 100 -fold dilution was initially prepared in $2 \%$ Optima grade $\mathrm{HNO}_{3}$. From this, a small (typically $20 \mu \mathrm{L}$ ) aliquot of each fraction was withdrawn and added to $4 \mathrm{~mL}$ scintillation 
cocktail in a 2-dram polyethylene vial. The samples were then allowed to decay through one or more half-lives prior to alpha decay rate measurement by LSA (TriCarb 1900CA, PerkinElmer). Using the counting region between 40 and 2000 channels (and using quench correction via the "transformed spectral index of the external standard" (tSIE)), the measurements assured integration of the ${ }^{211} \mathrm{At}$ and ${ }^{211} \mathrm{Po}$ alpha emissions (5.87 and 7.45 MeV, respectively). Since ${ }^{211} \mathrm{At}$ decays by alpha emission either via ${ }^{211}$ At directly or through ${ }^{211} \mathrm{Po}$, the sum of the two alpha peaks yielded the activity of ${ }^{211} \mathrm{At}$ in the sample. All ${ }^{211} \mathrm{At}$ activities were decay corrected to endof-bombardment (EOB).

\subsection{Bismuth analysis}

Aliquots of the collected TDB effluent fractions were initially sampled and diluted 100-fold into $2 \%$ Optima grade $\mathrm{HNO}_{3}$ (see Section 2.5). After complete decay of ${ }^{211} \mathrm{At}$, further dilutions using $2 \%$ Optima grade $\mathrm{HNO}_{3}$ were performed to achieve the appropriate $\mathrm{Bi}$ concentration range for analysis. The resulting solutions were analyzed using an iCap 6500 Duo (Thermo Scientific, Waltham, MA) inductively coupled plasma-optical emission spectrometer (ICP-OES) with analysis performed in axial mode. A six-point calibration curve was prepared for the Bi analysis by gravimetric dilutions of a $1000 \mu \mathrm{g} \cdot \mathrm{mL}^{-1}$ certified Bi standard purchased from High Purity Standards (Charleston, SC). All calibration curves used for the Bi concentrations reported herein had regression coefficients greater than 0.9999 .

\subsection{UV-Vis spectroscopic analysis}

UV-Vis absorbance spectroscopy was used to evaluate changes in the absorbance of a solution of freshly dissolved $\mathrm{Bi}$ metal in $10 \mathrm{M} \mathrm{HNO}_{3}$ as a function of time. The dissolved metal 
solution was stored uncapped, and aliquots were transferred to $1 \mathrm{~cm}$ path length disposable cuvettes made from PMMA (poly(methyl methacrylate)) to obtain absorbance spectra at elapsed time intervals. Prior to each measurement, the samples were referenced to a cuvette containing Bi-free $10 \mathrm{M} \mathrm{HNO}_{3}$.

The spectroscopic system was configured as follows: solarization resistant optical fibers (600 $\mu \mathrm{m}$ diameter fiber cores with SMA 905 connectors) were used to couple the light source, a variable attenuator (restricts light intensity from the light source), a cuvette holder, and a spectrometer. The light source was a tungsten and deuterium lamp (AIS, Flemington, NJ). The spectrometer was an electrically cooled QE Pro with 200-950 nm wavelength range, variable groove density grating, and thin-backed 2D array detector with a variable longpass order-sorting filter (Ocean Optics, Dunedin, FL). Spectrometer operation and data collection used OceanView software (v. 1.5.2) (Ocean Optics).

\subsection{Bi metal dissolution rates}

Surface area normalized Bi metal dissolution rates $\left(R_{d}\right)$, performed in open vessels, were determined for $\mathrm{HNO}_{3}$ concentrations between 6 and 15.8 moles $\cdot \mathrm{L}^{-1}(6,8,12$, and $15.8 \mathrm{M})$. A 25 $\mathrm{mL}$ volume of $\mathrm{HNO}_{3}$ was added to a $50 \mathrm{~mL}$ beaker and the liquid was stirred using a magnetic stir bar. At time zero, cylindrical Bi metal pieces of known mass and surface area (surface area was determined by measuring length and diameter of each piece by caliper) were added to the various $\mathrm{HNO}_{3}$ solutions. Samples $(10 \mu \mathrm{L})$ were obtained from the stirred solution at recorded time intervals. These samples were diluted into $2 \% \mathrm{HNO}_{3}$ for subsequent analysis by ICP-OES. Linear regression analysis was performed across the linear portion of the dissolution curves to obtain a surface area normalized Bi dissolution rate. Additionally, the method was validated at 
3.3, 5, and $10 \mathrm{M} \mathrm{HNO}_{3}$ using Bi metal pieces of known surface area by gravimetrically determining the loss of Bi mass over the elapsed acid contact time. Finally, the combined surface area normalized Bi dissolution rates as a function of $\mathrm{HNO}_{3}$ concentration were modeled as a simple two-parameter power function using SigmaPlot v. 13.0 (Systat Software, Inc., San Jose, CA).

\subsection{Bi metal dissolution and ${ }^{211}$ At release under flow conditions}

For the in-line Bi dissolution optimization studies, the Bi concentrations per fraction were determined by ICP-OES analysis, as described in Section 2.6. The cumulative dissolved Bi mass, as a function of collected $\mathrm{HNO}_{3}$ volume, was plotted, resulting in a sigmoidal curve. The linear portion of the sigmoidal curve was modeled by linear regression analysis; the slope of the line yielded the solubilized Bi concentration. Conversion of the TDB effluent Bi concentrations ([Bi]) to Bi dissolution rates $\left(R_{d}\right)$ at a given influent $\mathrm{HNO}_{3}$ concentration can be accomplished via eq 2 ,

where $A$ is the surface area of the Bi metal target $\left(\mathrm{cm}^{2}\right)$ and $R_{f}, V$, and $t_{r}$ are defined by eq 1 . When assessing the performance of the TDB on irradiated targets, cumulative Bi mass fractions and cumulative ${ }^{211} \mathrm{At}$ activity fractions were determined as a function of TDB effluent volume. Cumulative dissolved Bi mass fractions, $B i_{C}$, were calculated as per eq 3, 
where $f$ is the effluent fraction number, $n$ is the number of all fractions collected, $M_{B i, f}$ is the mass of Bi in each fraction $f$, and $M_{B i, t o t}$ is the total Bi mass collected across all fractions. Cumulative

${ }^{211}$ At activity fractions, ${ }^{211} A t_{C}$, were calculated in the same way (eq 4),

where $A_{A t, f}$ is the activity of ${ }^{211} \mathrm{At}$ in each fraction $f$, and $A_{A t, t o t}$ is the total ${ }^{211} \mathrm{At}$ activity collected across all fractions. Since the activity of ${ }^{211}$ At released from the target was routinely $>99 \%$ (see Section 2.5), only the activity collected in the TDB effluent fractions was considered in the ${ }^{211} A t_{C}$ calculations.

For the four irradiated targets dissolved by the TDB in this study, $B i_{C}$ and ${ }^{211} A t_{C}$ were plotted as a function of $\mathrm{HNO}_{3}$ volume collected across all fractions $(f=1$ to $n)$. The four data sets were then modeled as a global curve fit using a five parameter sigmoidal function using SigmaPlot (eq 5):

\section{Results and Discussion}

\subsection{Evaluating Bi metal dissolution with nitric acid}

\subsubsection{Bi dissolution reactions}

Nitric acid reacts at room temperature with $\mathrm{Bi}$ metal to form bismuth nitrate $\left(\mathrm{Bi}\left(\mathrm{NO}_{3}\right)_{3}\right)$ via the generalized reactions shown in the following equations. Nitric acid is reduced through a two- 
step process to yield first $\mathrm{HNO}_{2}$ and then $\mathrm{NO}$ by the consolidated half-reaction shown in eq 6; it has a standard reduction potential of $+0.957 \mathrm{~V}$ (Vanysek, 2014-2015).

The standard oxidizing potential of $\mathrm{Bi}^{0}$ to $\mathrm{Bi}^{+3}$ is $-0.308 \mathrm{~V}$ (eq 7) (Vanysek, 2014-2015).

This yields a net reaction with overall potential of $+0.649 \mathrm{~V}$ (eq 8):

The reaction between $\mathrm{Bi}^{0}$ and $\mathrm{HNO}_{3}$ to yield $\mathrm{Bi}\left(\mathrm{NO}_{3}\right)_{3}$ can generally be thought to proceed at a 1:4 stoichiometric ratio (eq 9):

In solutions containing high concentrations of $\mathrm{HNO}_{3}$, $\mathrm{Bi}$ metal dissolves to yield a green solution, as shown in Figure 3A. If $\mathrm{NO}_{\mathrm{x}}$ gases were prevented from escaping the vessel, the solution remained green for an extended period of time ( $>24 \mathrm{~h}$ ). If the solution was exposed to atmosphere, the $\mathrm{NO}_{\mathrm{x}}$ gases escaped, and the solution went from green to yellow to clear over a period of several hours (Figure 3B, C).

Evaluation of the solution by absorbance spectroscopy (Figure 3B) indicates an initial broad absorbance band between $\sim 300$ and $450 \mathrm{~nm}$. Over several hours, absorbance diminishes to yield an unabsorbing region between $\sim 400$ and $450 \mathrm{~nm}$ and a multi-component spectra between $\sim 300$ and $400 \mathrm{~nm}$. The drastic color change of the solution may be explained by the interaction of nitrogen oxides within the solution. In the presence of oxygen, NO gas (colorless) that does not immediately escape the aqueous solution during the reaction with $\mathrm{Bi}$ metal forms $\mathrm{NO}_{2}$ gas (yellow in solution). Nitrogen dioxide will in turn combine with $\mathrm{NO}$ to form $\mathrm{N}_{2} \mathrm{O}_{3}$, which is 
known to possess a blue color (Cotton and Wilkinson, 1988). Equilibrium of these nitrogen oxides in solution forms an equilibrium with $\mathrm{HNO}_{2}$ via eq 10 (Jones, 1973; Klemenc, 1955).

It has been noted that green solutions of $\mathrm{HNO}_{3}$ can be the result of this equilibrium of the blue and yellow species (Jones, 1973).

The compilation of absorbance spectra of the aging Bi-containing $\mathrm{HNO}_{3}$ solution (Figure 3B) exhibits a series of absorbance bands (times $d-j$ ) that seem to indicate the presence of $\mathrm{HNO}_{2}$ (Amado et al., 2001; Arakaki et al., 1999; Johnston and Graham, 1974). The diminishment of these bands indicates loss of $\mathrm{HNO}_{2}$ over time, which can be explained by the progression of the eq 10 reaction to $\mathrm{HNO}_{3}, \mathrm{NO}(\mathrm{g})$, and $\mathrm{H}_{2} \mathrm{O}$ as per eq 11 (Jones, 1973; Klemenc, 1955).

It should be noted that the single spectral peak at $\sim 337 \mathrm{~nm}$ (time $k$ ) persisted between 23.5 and $>72 \mathrm{~h}$. The peak position and shape closely matched the absorbance spectrum obtained by dissolving $\mathrm{Bi}\left(\mathrm{NO}_{3}\right)_{3} \cdot 5 \mathrm{H}_{2} \mathrm{O}$ salts into $10 \mathrm{M} \mathrm{HNO}_{3}$. This observation led us to conclude that the persistent $\sim 337 \mathrm{~nm}$ spectral component was $\mathrm{Bi}\left(\mathrm{NO}_{3}\right)_{3}$ in solution. Additionally, the lack of multiple spectral bands $(\sim 350-400 \mathrm{~nm})$ in the dissolved $\mathrm{Bi}\left(\mathrm{NO}_{3}\right)_{3} \cdot 5 \mathrm{H}_{2} \mathrm{O}$ salts provided further evidence that the multi-component spectral bands shown in Fig. 3B were due to the presence of $\mathrm{HNO}_{2}$ in solution that was formed by the reduction products of $\mathrm{HNO}_{3}$ formed during $\mathrm{Bi}^{0} \rightarrow \mathrm{Bi}^{+3}$ oxidation.

\subsection{2 $B i^{0}$ dissolution rates}

The rates of $\mathrm{Bi}$ metal dissolution, normalized to the surface area of the metal pieces $\left(R_{d}\right.$, $\left.\mathrm{mg} \cdot\left(\mathrm{cm}^{2} \cdot \mathrm{s}\right)^{-1}\right)$, were measured in solutions of $\mathrm{HNO}_{3}$ between 3.3 and 15.8 moles $\cdot \mathrm{L}^{-1}$ in open 
vessels (Figure 4, main). The rate data was modeled using a simple 2-parameter power function to yield the curve $R_{d}=(5.9 \pm 2.4) \times 10^{-5} \cdot\left[\mathrm{HNO}_{3}\right]^{(4.00 \pm 0.15)}\left(\mathrm{R}^{2}=0.998\right)$. The curve indicates that Bi dissolution rate increases with the fourth power of the $\mathrm{HNO}_{3}$ molar concentration. While $\mathrm{HNO}_{3}$ concentration greatly affects the dissolution rate of $\mathrm{Bi}$ metal, the resulting $\mathrm{Bi}\left(\mathrm{NO}_{3}\right)_{3}$ solubility tends to decrease with increasing $\mathrm{HNO}_{3}$ concentration. It was therefore concluded that for application to flow-through dissolution of Bi metal to recover the short-lived ${ }^{211} \mathrm{At}$, the $\mathrm{HNO}_{3}$ concentration needed to be maximized to the extent possible to assure fast metal dissolution rates, while assuring that excessive $\mathrm{Bi}\left(\mathrm{NO}_{3}\right)_{3}$ salt formation did not occur within the flow chamber. The following section describes the evaluation of Bi metal dissolution performance under flow conditions using the TDB.

\subsection{In-line Bi target dissolution: system optimization}

Bi metal dissolution with $\mathrm{HNO}_{3}$ was evaluated with non-irradiated cyclotron targets using the TDB assembly (Figure 2) coupled to a computer controlled fluid delivery system (Figure 1). The concentration of $\mathrm{Bi}$ in the TDB effluents was evaluated by varying the $\mathrm{HNO}_{3}$ influent concentration (with fixed flow rate) and by varying the flow rate (with fixed influent $\mathrm{HNO}_{3}$ concentration).

\subsubsection{Varied $\mathrm{HNO}_{3}$ concentration}

Table 2 lists the dissolved Bi concentrations that emerged from the TDB effluent port as $\mathrm{HNO}_{3}$ concentration was varied between 4 and 12 moles $\cdot \mathrm{L}^{-1}$ and the flow rate was fixed at 0.5 $\mathrm{mL} \cdot \mathrm{min}^{-1}$. Reliable Bi concentration data could not be obtained at $12 \mathrm{M} \mathrm{HNO}_{3}$, as the resulting effluent fractions appeared to be saturated with $\mathrm{Bi}\left(\mathrm{NO}_{3}\right)_{3}$ salts. Therefore, $10 \mathrm{M} \mathrm{HNO}_{3}$ was determined to be optimal, given its ability to achieve the highest dissolved Bi concentration 
( $\left.\sim 40 \mathrm{~g} \cdot \mathrm{L}^{-1}\right)$ without exceeding the $\mathrm{Bi}\left(\mathrm{NO}_{3}\right)_{3}$ solubility limit. While $12 \mathrm{M} \mathrm{HNO}_{3}$ undoubtedly provided faster rates of $\mathrm{Bi}$ metal dissolution (Figure 4, main), the observation that the $\mathrm{Bi}\left(\mathrm{NO}_{3}\right)_{3}$ solubility limit was exceeded in this higher acid concentration placed $12 \mathrm{M} \mathrm{HNO}_{3}$ beyond the feasible range for routine use within the in-line target dissolution apparatus. This is because excessive salt formation within the flow apparatus could potentially plug the effluent line, which in turn could create back-pressure within the TDB chamber. Such an occurrence could lead to a leak of dissolver solution around the Viton ${ }^{\mathrm{TM}} \mathrm{O}$-ring seal that forms the barrier between the $\mathrm{Al}$ target rim and the TDB front panel.

Linear regression analysis of the $\mathrm{Bi}$ concentrations when using $4 \mathrm{M}$ through $10 \mathrm{M} \mathrm{HNO}_{3}$ influent solutions (Table 2) indicates that dissolved Bi concentrations increase with a slope of $67.1 \pm 4.5 \mathrm{~g} \mathrm{Bi} \cdot \mathrm{L}^{-1}$ per molar concentration of $\mathrm{HNO}_{3}$, and a y-intercept of $-220 \pm 33 \mathrm{~g} \mathrm{Bi} \cdot \mathrm{L}^{-1}\left(\mathrm{R}^{2}\right.$ $=0.991)$. Conversion of the TDB effluent Bi concentrations $([B i])$ to Bi dissolution rates $\left(R_{d}\right)$ at a given influent $\mathrm{HNO}_{3}$ concentration is performed by eq 2. Figure 4 (inset) plots the converted TDB dissolution rate data $(\square)$ with the fitted open-vessel Bi dissolution rate curve (same as in main plot). While the TDB effluent dissolution rate data approximates the modeled open-vessel dissolution rate between $4 \mathrm{M}$ and $\sim 7 \mathrm{M} \mathrm{HNO}_{3}$, the modeled open-vessel rate makes a dramatic departure from the observed TDB rates thereafter. Whereas a detailed study into the complex and dynamic chemical processes occurring within the TDB chamber is warranted, it is beyond the scope of the current research. A likely explanation for the suppressed nature of the TDB $R_{d}$ values vs. the open-vessel $R_{d}$ values at higher $\mathrm{HNO}_{3}$ concentrations is the consumption of the influent reactant. Because the $\mathrm{Bi}^{0}-\mathrm{HNO}_{3}$ reaction rate exceeds the rate of delivery $\left(R_{f}\right)$ of fresh $\mathrm{HNO}_{3}$ into the block, the net $\mathrm{Bi}$ dissolution rate is suppressed as the influent $\mathrm{HNO}_{3}$ is consumed 
in the reaction. This effect is more pronounced at higher $\mathrm{HNO}_{3}$ concentrations because the rate of reaction with $\mathrm{Bi}^{0}$ is increasing at a rate to the forth power of the $\mathrm{HNO}_{3}$ concentration.

\subsubsection{Varied influent flow rate}

Next, the effect of influent flow rate on dissolved $\mathrm{Bi}$ concentration was evaluated $\left(\mathrm{HNO}_{3}\right.$ concentration fixed at 10 moles $\left.\cdot \mathrm{L}^{-1}\right)$. The residence time $\left(t_{r}\right)$ of influent $\mathrm{HNO}_{3}$ into the TDB flow channel is related to the flow rate as per eq 1 . The data indicates that Bi concentration is not greatly affected by flow rate, as the determined concentrations were quite similar, despite the order of magnitude change in flow rate (and corresponding $t_{r}$ ) through the TDB (Table 3 ). This suggests that the $\mathrm{Bi} / \mathrm{HNO}_{3}$ reaction kinetics are quite fast. The empirical results for the $\mathrm{Bi}$ concentration $\left([B i], \mathrm{g} \cdot \mathrm{L}^{-1}\right)$ as a function of $t_{r}(\mathrm{~s})$ were fitted as a quadratic function, where $[B i]=-0.0252 t_{r}^{2}+3.75 t_{r}+302\left(\mathrm{R}^{2}=1.00\right)$.

At the dissolver solution concentration of $10 \mathrm{M} \mathrm{HNO}_{3}$, the $0.5 \mathrm{~mL} \cdot \mathrm{min}^{-1}$ flow rate $\left(t_{r}=61.5\right.$ s) provided the maximum observed Bi concentration in the effluent solution $\left(438 \pm 13 \mathrm{~g} \mathrm{Bi} \cdot \mathrm{L}^{-1}\right)$. Therefore, these two parameters were selected as conditions for optimal in-line Bi target dissolution performance. Next, the TDB and associated fluid delivery system were configured within the radiological glovebox dedicated to ${ }^{211}$ At purification for evaluation of the system performance on cyclotron irradiated Bi target assemblies.

\subsection{In-line dissolution of irradiated Bi targets}

Four irradiated Bi target assemblies were processed using the TDB and fluidic system. The system was programmed to deliver $20 \mathrm{~mL}$ of $10 \mathrm{M} \mathrm{HNO}_{3}$ at $0.5 \mathrm{~mL} \cdot \mathrm{min}^{-1}$ as per the protocol described in Table 1. Table 4 provides a summary of the Bi metal target masses, cyclotron irradiation parameters, and resulting ${ }^{211} \mathrm{At}$ activities for each of the four targets. The four Bi 
target assemblies provided consistent Bi metal target masses $(4.43 \pm 0.15 \mathrm{~g})$, with a mean ${ }^{211} \mathrm{At}$ production yield of $1.06 \pm 0.07 \mathrm{GBq}$.

The mean Bi metal dissolution profile across the four irradiated targets, as a function of dissolver solution volume collected from the TDB, is shown in Figure 5A. The data shows a plateau of Bi concentration at $445 \pm 12 \mathrm{~g} \cdot \mathrm{L}^{-1}$ after $\sim 3-6 \mathrm{~mL} 10 \mathrm{M} \mathrm{HNO}_{3}$ solution was collected from the TDB. Between $\sim 6$ and $10 \mathrm{~mL}$, the Bi concentration began to drop gently as the $\mathrm{Bi}$ metal within the target was consumed and the aluminum backing was exposed. Beyond $\sim 10 \mathrm{~mL}$, the concentration of Bi dropped dramatically and asymptotically approached zero until $\sim 16 \mathrm{~mL}$ of $\mathrm{HNO}_{3}$ solution was collected. Inspection of each of these Bi target assemblies at the conclusion of the $20 \mathrm{~mL} \mathrm{HNO}_{3}$ solution deliveries indicated that dissolution of the $\mathrm{Bi}$ metal target was complete, as only the aluminum backings were visible (Figure 6).

In a prior in-line dissolution experiment, ${ }^{1}$ a target was sacrificed before $100 \%$ of the Bi was dissolved in order to observe the Bi etching process within the TDB. The partially digested target indicated that the acid etching of the Bi metal films was not uniform within the chamber (e.g., the Bi metal films did not etch uniformly in thickness). Rather, the acid eventually etched channels around the central upper portion of the Bi metal layer, thus creating a thin "island" of $\mathrm{Bi}$ along the center of the Bi deposit region atop the aluminum backing (Figure 6, inset). The asymptotic decrease in $\mathrm{Bi}$ concentration towards the end of the dissolution cycles is likely caused by the diminishment of this reactive surface.

The corresponding ${ }^{211}$ At activity concentration vs. collected TDB effluent volume is shown in Figure 5B. The ${ }^{211} \mathrm{At}$ release data shows an immediate concentration maximum at $\sim 3 \mathrm{~mL}$,

\footnotetext{
${ }^{1}$ Data from this experiment was not used in dissolution performance analysis
} 
followed by a drop and plateau between $\sim 5-8 \mathrm{~mL}$. Between $\sim 8$ and $\sim 11 \mathrm{~mL}$, the ${ }^{211} \mathrm{At}$ release activity drops gently, and then drops asymptotically between $\sim 11 \mathrm{~mL}$ and $\sim 16 \mathrm{~mL}$.

The cumulative Bi mass fractions ( $B i_{C}$, eq 3$)$ and cumulative ${ }^{211} \mathrm{At}$ activity fractions $\left({ }^{211} A t_{C}\right.$, eq 4) for the four processed irradiated Bi targets are shown overlaid in Figure 7. The solid lines are modeled five parameter sigmoidal curves, with the resulting fit estimates listed in Table 5. The modeled curves suggest that $90 \%, 95 \%$, and $97.5 \%$ of the Bi mass fraction was removed in $10.8,12.1$, and $13.4 \mathrm{~mL}$, respectively, while $90 \%, 95 \%$, and $97.5 \%$ of the ${ }^{211}$ At activity fraction

was recovered within $11.8,13.4$, and $14.9 \mathrm{~mL}$, respectively. The reason for the slight retardation in ${ }^{211} \mathrm{At}$ release from the TDB with respect to Bi release fraction is not obvious; it may be indicative of a subtle binding affinity of ${ }^{211} \mathrm{At}$ on the exposed aluminum target assembly surface. This aluminum surface would be passivated through the formation of aluminum oxide via the reaction of strong $\mathrm{HNO}_{3}$ with $\mathrm{Al}^{0}$.

\section{Summary and Conclusions}

In open vessels, the Bi metal dissolution rate $\left(R_{d}, \mathrm{mg} \cdot\left(\mathrm{cm}^{2} \cdot \mathrm{s}\right)^{-1}\right)$ in nitric acid was shown to increase according to the approximated function $R_{d}=6 \times 10^{-5} \cdot\left[\mathrm{HNO}_{3}\right]^{4}$, revealing a strong dependence on $\mathrm{HNO}_{3}$ concentration. The observed rate function was used to compare and contrast Bi dissolution rate behavior within the confines of an in-line Bi target dissolution apparatus. Additionally, spectral analysis of freshly dissolved $\mathrm{Bi}$ metal in strong $\mathrm{HNO}_{3}$ indicated a complex and dynamic mixture of $\mathrm{HNO}_{3}$ reaction byproducts that are responsible for the temporary green color of the solution.

An automated fluid delivery module, comprising a syringe pump and an in-line Bi target dissolution block (TDB) was designed and assembled. The performance of the in-line 
dissolution chamber was evaluated across a range of $\mathrm{HNO}_{3}$ concentrations and influent flow rates to determine how these variables affect the solubilization of Bi from the target assembly. It was determined that $10 \mathrm{M} \mathrm{HNO}_{3}$ delivered at $0.5 \mathrm{~mL} \cdot \mathrm{min}^{-1}$ provided the highest $\mathrm{Bi}$ concentrations in the effluent solution. While the concentration of $\mathrm{HNO}_{3}$ influent solution had a dramatic effect on resultant Bi concentration in the TDB effluent, the effect of influent flow rate on resulting dissolved Bi concentrations was demonstrated to produce modest variations in target dissolution performance. Therefore, operation of the TDB at flow rates greater than 0.5 $\mathrm{mL} \cdot \mathrm{min}^{-1}$ can be considered. While $\mathrm{HNO}_{3}$ concentrations above $10 \mathrm{moles} \cdot \mathrm{L}^{-1}$ result in faster $\mathrm{Bi}$ metal dissolution rates, the observed formation of $\mathrm{Bi}\left(\mathrm{NO}_{3}\right)_{3}$ salts in the effluent solution at 12 moles $\cdot \mathrm{L}^{-1}$ precluded its use due to concerns of possible plugging of the dissolution block effluent port.

The optimized system was used to process four cyclotron irradiated Bi targets that contained $4.43 \pm 0.15 \mathrm{~g} \mathrm{Bi}$ and $1.06 \pm 0.07 \mathrm{GBq}{ }^{211} \mathrm{At}(\mathrm{EOB})$. The resulting Bi metal and ${ }^{211} \mathrm{At}$ release fractions were measured as a function of $\mathrm{HNO}_{3}$ solution effluent volume. The data indicates that the fluidic system is capable of performing highly reproducible target dissolutions, with cumulative Bi and ${ }^{211}$ At collection rates modeled as sigmoidal functions. The sigmoidal functions, in turn, provide a means for the operator to choose the desired ${ }^{211} \mathrm{At}$ recovery fraction by setting the dissolver solution delivery parameters. The described target dissolution module has been integrated into the ${ }^{211}$ At purification process performed at the University of Washington. With this module being complete, the research team has begun to integrate laboratory automation into the subsequent ${ }^{211}$ At purification steps. 


\section{Acknowledgements}

This work was funded by the U.S. Department of Energy Office of Science, Isotope

Development and Production for Research and Applications (IDPRA) subprogram of the Office of Nuclear Physics (PNNL Award \# DE-AC05-76RL01830, FWP 63816; University of Washington Award \# DE-SC0010502). Pacific Northwest National Laboratory (PNNL) is a multiprogram National Laboratory operated for DOE by Battelle. The authors would like to acknowledge David E. Nelson (PNNL) for machining the TDB.

\section{References}

Allen, B.J., Raja, C., Rizvi, S., Li, Y., Tsui, W., Zhang, D., Song, E., Qu, C.F., Kearsley, J., Graham, P., Thompson, J., 2004. Targeted alpha therapy for cancer. Phys Med Biol 49, 3703-3712.

Alliot, C., Cherel, M., Barbet, J., Sauvage, T., Montavon, G., 2009. Extraction of astatine-211 in diisopropylether (DIPE). Radiochim Acta 97, 161-165.

Amado, S., Blakelock, L., Holmes, A.J., Williams, D.L.H., 2001. Kinetics and mechanism of the formation and reactions of S-nitroso derivatives of some heterocyclic thiones. J Chem Soc, Perkin Trans 2, 441-447.

Andersson, H., Cederkrantz, E., Bäck, T., Divgi, C., Elgqvist, J., Himmelman, J., Horvath, G., Jacobsson, L., Jensen, H., Lindegren, S., Palm, S., Hultborn, R., 2009. Intraperitoneal $\alpha$-particle radioimmunotherapy of ovarian cancer patients: Pharmacokinetics and dosimetry of ${ }^{211}$ At-MX35 $\mathrm{F}\left(\mathrm{ab}^{\prime}\right)_{2}$ - A phase I study. J Nucl Med 50, 1153-1160.

Aneheim, E., Albertsson, P., Bäck, T., Jensen, H., Palm, S., Lindegren, S., 2015a. Automated astatination of biomolecules - a stepping stone towards multicenter clinical trials. Scientific Reports 5, 1-11.

Aneheim, E., Jensen, H., Albertsson, P., Lindegren, S., 2015b. Astatine-211 labeling: a study towards automatic production of astatinated antibodies. J Radioanal Nucl Chem 303, 979-983. Arakaki, T., Miyake, T., Hirakawa, T., Sakugawa, H., 1999. pH dependent photoformation of hydroxyl radical and absorbance of aqueous-phase $\mathrm{N}(\mathrm{III})\left(\mathrm{HNO}_{2}\right.$ and $\left.\mathrm{NO}_{2}{ }^{-}\right)$. Environ Sci Technol 33, 2561-2565.

Bäck, T.A., Chouin, N., Lindegren, S., Kahu, H., Jensen, H., Albertsson, P., Palm, S., 2016. Cure of human ovarian carcinoma solid xenografts by fractionated $\left[{ }^{211} \mathrm{At}\right]$ alpha-radioimmunotherapy: Influence of tumor absorbed dose and effect on long-term survival. J Nucl Med (10.2967/ jnumed.116.178327). 
Balkin, E.R., Hamlin, D.K., Gagnon, K., Chyan, M.-K., Pal, S., Watanabe, S., Wilbur, D.S., 2013. Evaluation of a wet chemistry method for isolation of cyclotron produced $\left[{ }^{211} \mathrm{At}\right]$ astatine. Applied Sci 3, 636-655.

Barbet, J., Chatal, J.-F., 2011. The best radionuclide for radioimmunotherapy of small tumors: beta- or alpha-emitter? Eur J Nucl Med Mol Imaging 38, 271-273.

Behr, T.M., Béhé, M., Stabin, M.G., Wehrmann, E., Apostolidis, C., Molinet, R., Strutz, F., Fayyazi, A., Wieland, E., Gratz, S., Koch, L., Goldenberg, D.M., Becker, W., 1999. High-Linear Energy Transfer (LET) $\alpha$ versus low-LET $\beta$ emitters in radioimmunotherapy of solid tumors: Therapeutic efficacy and dose-limiting toxicity of ${ }^{213} \mathrm{Bi}$ - versus ${ }^{90}$ Y-labeled CO17-1A Fab' fragments in a human colonic cancer model. Cancer Res 59, 2635-2643.

Cotton, F.A., Wilkinson, G., 1988. Nitrogen: Group VA (15), Advanced Inorganic Chemistry. John Wiley \& Sons, New York, pp. 305-381.

Couturier, O., Supiot, S., Degraef-Mougin, M., Faivre-Chauvet, A., Carlier, T., Chatal, J.F., Davodeau, F., Cherel, M., 2005. Cancer radioimmunotherapy with alpha-emitting nuclides. Eur J Nucl Med Mol Imaging 32, 601-614.

Dahle, J., Abbas, N., Bruland, O.S., Larsen, R.H., 2011. Toxicity and relative biological effectiveness of alpha emitting radioimmunoconjugates. Curr Radiopharm 4, 321-328. Gagnon, K., Risler, R., Pal, S., Hamlin, D., Orzechowski, J., Pavan, R., Zeisler, S., Wilbur, D.S., 2012. Design and evaluation of an external high-current target for production of ${ }^{211}$ At. J Labelled Compd Radiopharm 55, 436-440.

Green, D.J., Shadman, M., Jones, J.C., Frayo, S.L., Kenoyer, A.L., Hylarides, M.D., Hamlin, D.K., Wilbur, D.S., Balkan, E.R., Lin, Y., Miller, B.W., Frost, S.H.L., Gopal, A.K., Orozco, J.J., Gooley, T.A., Laird, K.L., Till, B.G., Bäck, T., Sandmaier, B.M., Pagel, J.M., Press, O.W., 2015. Astatine-211 conjugated to an anti-CD20 monoclonal antibody eradicates disseminated B-cell lymphoma in a mouse model. Blood 125, 2111-2119.

Groppi, F., Bonardi, M.L., Birattari, C., Menapace, E., Abbas, K., Holzwarth, U., Alfarano, A., Morzenti, S., Zona, C., Alfassi, Z.B., 2005. Optimisation study of $\alpha$-cyclotron production of At-211/Po-211g for high-LET metabolic radiotherapy purposes. Appl Radiat Isot 63, 621-631. Guerard, F., Gestin, J.F., Brechbiel, M.W., 2013. Production of $\left[{ }^{211} \mathrm{At}\right]$-astatinated radiopharmaceuticals and applications in targeted alpha-particle therapy. Cancer Biother Radiopharm 28, 1-20.

Hassfjell, S., Brechbiel, M.W., 2001. The development of the $\alpha$-particle emitting radionuclides ${ }^{212} \mathrm{Bi}$ and ${ }^{213} \mathrm{Bi}$, and their decay chain related radionuclides, for therapeutic applications. Chem Rev 101, 2019-2036.

IAEA, 2009. Technical Report Series No. 468: Cyclotron Produced Radionuclides: Physical Characteristics and Production Methods. International Atomic Energy Agency, Vienna.

Johnson, G.L., Leininger, R.F., Segre, E., 1949. Chemical Properties of Astatine. I. J Chem Phys $17,1-10$.

Johnston, H.S., Graham, R., 1974. Photochemistry of $\mathrm{NO}_{\mathrm{x}}$ and $\mathrm{HNO}_{\mathrm{x}}$ compounds. Can J Chem 52, 1415-1423.

Jones, K., 1973. Dinitrogen Trioxide, Pergamon Texts in Inorganic Chemistry Vol. II: The Chemistry of Nitrogen. Pergamon Press, Oxford, pp. 335-340. 
Jurcic, J.G., Larson, S.M., Sgouros, G., McDevitt, M.R., Finn, R.D., Divgi, C.R., Ballangrud, Å.M., Hamacher, K.A., Ma, D., Humm, J.L., Brechbiel, M.W., Molinet, R., Scheinberg, D.A., 2002. Targeted $\alpha$ particle immunotherapy for myeloid leukemia. Blood 100, 1233-1239.

Klemenc, A., 1955. Zur Kenntnis der Salpetersäure. XI. Zeitsch anorg allgemeine Chem 280, 100-109.

Lambrecht, R.M., Mirzadeh, S., 1985. Cyclotron isotopes and radiopharmaceuticals- XXXV. Astatine-211. Int J Appl Radiat Isot 36, 443-450.

Lindegren, S., Bäck, T., Jensen, H.J., 2001. Dry-distillation of astatine-211 from irradiated bismuth targets: a time-saving procedure with high recovery yields. Appl Radiat Isot 55, 157-160.

McDevitt, M.R., Sgouros, G., Finn, R.D., Humm, J.L., Jurcic, J.G., Larson, S.M., Scheinberg, D.A., 1998. Radioimmunotherapy with alpha-emitting nuclides. Eur J Nucl Med 25, 1341-1351. Mulford, D.A., Scheinberg, D.A., Jurcic, J.G., 2005. The promise of targeted alpha-particle therapy. J Nucl Med 46 Suppl 1, 199S-204S.

Neirinckx, R.D., Smit, J.A., 1973. Separation of astatine-211 from bismuth metal. Anal Chim Acta 63, 201-204.

Neumann, H.M., 1957. Solvent distribution studies of the chemistry of astatine. J Inorg \& Nucl Chem 4, 349-353.

Orozco, J.J., Back, T., Kenoyer, A., Balkin, E.R., Hamlin, D.K., Wilbur, D.S., Fisher, D.R., Frayo, S.L., Hylarides, M.D., Green, D.J., Gopal, A.K., Press, O.W., Pagel, J.M., 2013. AntiCD45 radioimmunotherapy using ${ }^{211}$ At with bone marrow transplantation prolongs survival in a disseminated murine leukemia model. Blood 121, 3759-3767.

Rosenblat, T.L., McDevitt, M.R., Mulford, D.A., Pandit-Taskar, N., Divgi, C.R., Panageas, K.S., Heaney, M.L., Chanel, S., Morgenstern, A., Sgouros, G., Larson, S.M., Scheinberg, D.A., Jurcic, J.G., 2010. Sequential cytarabine and $\alpha$-particle immunotherapy with bismuth-213-Lintuzumab (HuM195) for acute myeloid leukemia. Clin Cancer Res 16, 5303-5311.

Sultana, M.S., Toyoshima, A., Mito, A., Takahashi, N., Baba, H., Watarai, H., 2000. Solvent extraction behavior of astatine and radioiodine at tracer concentrations. J Radioanal Nucl Chem 243, 631-634.

Vanysek, P., 2014-2015. Electrochemical Series, in: Haynes, W.M. (Ed.), Handbook of Chemistry and Physics, 95th ed. CRC Press, Boca Raton, FL, pp. 5-80 to 85-89.

Wilbur, D.S., 2008. [ $\left.{ }^{211} \mathrm{At}\right]$ Astatine-labeled compound stability: Issues with released $\left[{ }^{211} \mathrm{At}\right]$ astatide and development of labeling reagents to increase stability. Curr Radiopharm 1, 144-176.

Wilbur, D.S., 2011. Chemical and radiochemical considerations in radiolabeling with $\alpha$-emitting radionuclides. Curr Radiopharm 4, 214-247.

Wilbur, D.S., Hadley, S.W., Hines, J.J., Atcher, R.W., 1991. Assessment of dry distillation methods for improving protein labeling yields with astatine-211. J Labelled Compd Radiopharm 30, 214-215.

Wooten, A.L., Chyan, M.-K., Hamlin, D.K., Li, Y., Owsley, S.L., Jr., Niver, C.M., Krzysko, A.J., O'Hara, M.J., Wilbur, D.S., 2016. PEG column studies designed to eliminate nitric acid distillation in automation of the wet chemistry approach to isolation of astatine-211, 16th International Workshop on Targetry and Target Chemistry, Santa Fe, NM, p. 3. 
Yordanov, A.T., Pozzi, O., Carlin, S., Akabani, G., Wieland, B., Zalutsky, M., 2004. Wet harvesting of no-carrier-added ${ }^{211} \mathrm{At}$ from an irradiated ${ }^{209} \mathrm{Bi}$ target for radiopharmaceutical applications. J Radioanal Nucl Chem 262, 593-599.

Zalutsky, M.R., Pozzi, O.R., 2004. Radioimmunotherapy with alpha-particle emitting radionuclides. Q J Nucl Med Mol Imaging 48, 289-296.

Zalutsky, M.R., Pruszynski, M., 2011. Astatine-211: production and availability. Curr Radiopharm 4, 177-185.

Zalutsky, M.R., Reardon, D.A., Akabani, G., Coleman, R.E., Friedman, A.H., Friedman, H.S., McLendon, R.E., Wong, T.Z., Bigner, D.D., 2008. Clinical experience with $\alpha$-particle-emitting ${ }^{211} \mathrm{At}$ : Treatment of recurrent brain tumor patients with ${ }^{211} \mathrm{At}$-labeled chimeric antitenascin monoclonal antibody 81C6. J Nucl Med 49, 30-38.

Zalutsky, M.R., Reardon, D.A., Pozzi, O.R., Vaidyanathan, G., Bigner, D.D., 2007. Targeted alpha-particle radiotherapy with ${ }^{211}$ At-labeled monoclonal antibodies. Nucl Med Biol 34, 779-785.

Zona, C., Bonardi, M.L., Groppi, F., Morzenti, S., Canella, L., Persico, E., Menapace, E., Alfassi, Z.B., Abbas, K., Holzwarth, U., Gibson, N., 2008. Wet-chemistry method for the separation of no-carrier-added ${ }^{211} \mathrm{At} /{ }^{211} \mathrm{~g}$ Po from ${ }^{209} \mathrm{Bi}$ target irradiated by alpha-beam cyclotron. J Radioanal Nucl Chem 276, 819-824. 


\section{FIGURE CAPTIONS}

Figure 1. Schematic of a computer-controlled fluid delivery system comprising a syringe pump (SP) with 6-port distribution valve and $10 \mathrm{~mL}$ displacement syringe fluidically coupled to the target dissolution block (TDB), all of which is housed within a glovebox. Blue arrow indicates the Bi dissolving solution reagent influent line and green arrow indicates effluent collection line. Yellow/magenta line indicates the boundary of the radiological glovebox.

Figure 2. (A) Disassembled TDB components comprising the rear panel (RP), into which a Bi target assembly (T) is inserted, the front panel (FP), and stand (S). Black arrows show Teflon guide rods, green arrow shows the O-ring seal and $\mathrm{HNO}_{3}$ flow channel within, and white arrows show fastening clamps. (B) Fully assembled TDB atop the stand showing reagent influent (from syringe pump) and effluent ports. A Bi target assembly is visible through the semi-opaque viewing window.

Figure 3. (A) Freshly dissolved Bi metal using $10 \mathrm{M} \mathrm{HNO}_{3}$. (B) UV-Vis absorbance spectral overlays showing diminishment of absorbance regions over time (legend provides elapsed hours). (C) Solution turns colorless after being exposed to atmosphere for several hours.

Figure 4. Surface area normalized Bi metal dissolution rates (open vessel dissolution) as a function of $\mathrm{HNO}_{3}$ concentration (०). Line shows modeled fit (see text for equation) that indicates $\mathrm{Bi}$ dissolution rate is related to the forth power of $\mathrm{HNO}_{3}$ molar concentration. Inset: 
Zoomed view of the modeled $R_{d}$ curve (solid line) overlaid with calculated Bi metal dissolution rates from the TDB ( $\square)$ at $0.5 \mathrm{~mL} \cdot \mathrm{min}^{-1}$ flow rate.

Figure 5. (A) Mean Bi concentration as a function of delivered volume of $10 \mathrm{M} \mathrm{HNO}_{3}$ at a flow rate of $0.5 \mathrm{~mL} \cdot \mathrm{min}^{-1}$ for four irradiated Bi targets. (B) Mean ${ }^{211} \mathrm{At}$ release profile for the same four irradiated Bi targets. Error bars are $\pm 1 \sigma$ of the mean $(n=4)$.

Figure 6. Irradiated Bi target assembly in disassembled TDB after dissolution of Bi was complete. Only the aluminum backing is visible. Inset: Target assembly sacrificed before all Bi was dissolved by $\mathrm{HNO}_{3}$. Arrows show inlet and outlet flow direction. Inside the white line is a thin "island" of Bi metal that had not yet dissolved.

Figure 7. (A) Cumulative dissolved Bi mass fraction $\left(B i_{C}\right)$ as a function of collected $10 \mathrm{M}$ $\mathrm{HNO}_{3}$ volume $\left(0.5 \mathrm{~mL} \cdot \mathrm{min}^{-1}\right)$ from TDB $(\mathrm{n}=4)$. (B) Cumulative ${ }^{211} \mathrm{At}$ activity fraction $\left({ }^{211} \mathrm{At} C\right)$ for same. Line represents the modeled sigmoidal fit for the combined data sets. Fit estimate parameters are listed in Table 5. 
Table 1. Process steps for dissolution of Bi cyclotron targets with the TDB and associated fluid delivery system.

\begin{tabular}{|c|c|c|c|c|}
\hline Step & Description & $\begin{array}{l}\text { Reagent } \\
\text { delivery }\end{array}$ & $\begin{array}{l}\text { Vol., } \\
\mathrm{mL}\end{array}$ & $\begin{array}{c}\text { Flow rate, } \\
\mathrm{mL} / \mathrm{min}\end{array}$ \\
\hline 1 & Assemble target into TDB & & & \\
\hline \multirow{2}{*}{2} & \multirow{2}{*}{ Perform leak test protocol ${ }^{\mathrm{a}}$} & $\mathrm{H}_{2} \mathrm{O}$ & 6 & 10 \\
\hline & & Air & 6 & 10 \\
\hline 3 & Confirm positive O-ring seal & & & \\
\hline 4 & Target dissolution protocol ${ }^{\mathrm{a}}$ & $\mathrm{HNO}_{3}{ }^{\mathrm{b}}$ & 20 & $\operatorname{Vary}^{\mathrm{c}}$ \\
\hline \multirow{3}{*}{5} & \multirow{3}{*}{ TDB clean-up protocol ${ }^{\mathrm{a}}$} & Air & 4 & 10 \\
\hline & & $\mathrm{H}_{2} \mathrm{O}$ & 3 & 10 \\
\hline & & Air & 4 & 10 \\
\hline 6 & Remove spent Bi target & & & \\
\hline
\end{tabular}
a. Operation performed via computer control
b. $\mathrm{HNO}_{3}$ concentration varied between 4 and $12 \mathrm{M}$
c. Flow rate varied between 0.25 and $2.5 \mathrm{~mL} \cdot \mathrm{min}^{-1}$ 
Table 2. Dissolved $\mathrm{Bi}$ concentrations attained at varying $\mathrm{HNO}_{3}$ concentrations from the $\mathrm{TDB}$ at a flow rate of $0.5 \mathrm{~mL} \cdot \mathrm{min}^{-1}$.

\begin{tabular}{ccc}
\hline $\begin{array}{l}\text { Acid } \\
\text { conc., } \\
M\end{array}$ & $\begin{array}{l}{[\mathrm{Bi}],} \\
\mathrm{g} \cdot \mathrm{L}^{-1} \\
( \pm 1 \sigma)\end{array}$ & Replicates \\
\hline 4 & $34 \pm 2^{\mathrm{a}}$ & 1 \\
\hline 6 & $199 \pm 2^{\mathrm{a}}$ & 1 \\
\hline 8 & $329 \pm 3^{\mathrm{a}}$ & 1 \\
\hline 10 & $438 \pm 13$ & 5 \\
\hline 12 & $---\mathrm{b}$ & 1 \\
\hline
\end{tabular}

a. Uncertainty reported as the slope error of the linear regression

b. Fraction volumes indicated that $\mathrm{Bi}\left(\mathrm{NO}_{3}\right)_{3}$ solubility limit had been exceeded 
Table 3. Dissolved Bi concentrations attained at increasing flow rates (and corresponding residence times, $t_{r}$, of the acid) from the TDB at a $\mathrm{HNO}_{3}$ concentration of $10 \mathrm{moles} \cdot \mathrm{L}^{-1}$.

\begin{tabular}{lccc}
\hline $\begin{array}{l}\text { Flow } \\
\text { Rate, } \\
\mathrm{mL} / \mathrm{min}\end{array}$ & $t_{r}$, & $\begin{array}{l}{[\mathrm{Bi}],} \\
\mathrm{g} \cdot \mathrm{L}^{-1} \\
( \pm 1 \sigma)\end{array}$ & Replicates \\
\hline 0.25 & 123 & $382 \pm 28$ & 2 \\
\hline 0.50 & 61.5 & $438 \pm 13$ & 5 \\
\hline 1.0 & 30.8 & $393 \pm 3^{\mathrm{b}}$ & 1 \\
\hline 2.5 & 12.3 & $345 \pm 5^{\mathrm{b}}$ & 1 \\
\hline
\end{tabular}

a. $t_{r}$ given by eq 1

b. Uncertainty reported as the slope error of the linear regression 
Table 4. Bi target masses, cyclotron irradiation details, and resulting ${ }^{211}$ At yields.

\begin{tabular}{|c|c|c|c|c|c|c|c|}
\hline \multirow{3}{*}{ Target } & \multirow{3}{*}{$\begin{array}{c}\text { Bi target } \\
\text { mass, } \\
\mathrm{g}\end{array}$} & \multicolumn{4}{|c|}{ Cyclotron irradiation information } & \multirow{2}{*}{\multicolumn{2}{|c|}{${ }^{211}$ At activity ${ }^{b}$}} \\
\hline & & & Electric & & Integrated & & \\
\hline & & $\mathrm{MeV}$ & $\mu \mathrm{A}$ & $\min$ & $\mu \mathrm{A} \cdot \mathrm{h}^{\mathrm{a}}$ & $\mathrm{GBq}$ & $\mathrm{mCi}$ \\
\hline 1 & 4.58 & 29.0 & $45-50$ & 50 & 36 & 1.06 & 28.6 \\
\hline 2 & 4.45 & 29.0 & $35-40$ & 60 & 36 & 1.07 & 29.0 \\
\hline 3 & 4.23 & 29.0 & 34-39 & 64 & 36 & 1.03 & 27.9 \\
\hline 4 & 4.48 & 29.0 & $30-36$ & 75 & 38 & 1.09 & 29.5 \\
\hline $\begin{array}{l}\text { Mean, } \\
\text { error }\end{array}$ & $\begin{array}{c}4.43 \\
\pm 0.15^{\mathrm{c}}\end{array}$ & 29.0 & --- & --- & --- & $\begin{array}{c}1.06 \\
\pm 0.07 \mathrm{~d}\end{array}$ & $\begin{array}{c}28.8 \\
\pm 2.0^{\mathrm{d}}\end{array}$ \\
\hline
\end{tabular}
a. Fixed end-point of irradiation via beam current integrator
b. At end-of-bombardment
c. $\pm 1 \sigma$ of the mean
d. Propagated error based on $\pm 3.4 \%$ uncertainty in each measurement 
Table 5. Modeled fit estimates and resulting $\mathrm{R}^{2}$ values for cumulative $\mathrm{Bi}$ mass fractions and ${ }^{211}$ At activity fractions as a function of collected $\mathrm{HNO}_{3}$ volumes across four dissolved Bi targets. ${ }^{\mathrm{a}}$

\begin{tabular}{ccc}
$\begin{array}{c}\text { Sigmoidal } \\
\text { parameter }^{\mathrm{b}}\end{array}$ & $\mathrm{Bi}$ & ${ }^{211} \mathrm{At}$ \\
\hline $\mathrm{y}_{0}$ & -3.5 & -15 \\
$\mathrm{a}$ & 4.5 & 16 \\
$\mathrm{x}_{0}$ & 10.3 & 11.3 \\
$\mathrm{~b}$ & 1.5 & 1.8 \\
$\mathrm{c}$ & 0.04 & 0.01 \\
\hline $\mathrm{R}^{2}$ & 0.9979 & 0.9953 \\
\hline
\end{tabular}

a. Modeled fit shown in Figure 7

b. As per eq 5 